\title{
Protective effect of crude polysaccharide from Pao-Tian- Xiong derived from monkshood, against chronic renal failure in mice
}

\author{
Lin Wang ${ }^{1}$, Runyong Fan ${ }^{1}$, Funeng Geng ${ }^{2}$, Yongxiang Gao ${ }^{3}$, Qinwan Huang ${ }^{1 *}$ \\ ${ }^{1}$ College of Pharmacy, Chengdu University of Traditional Chinese Medicine, No. 1166, Liutai Road, Wenjiang District, Chengdu \\ 611137, 'Sichuan Good Doctor Pharmaceutical Group Co. Ltd, No. 88, Yingmenkou Road, Jinniu District, Chengdu 610031, \\ ${ }^{3}$ College of Basic Medicine, Chengdu University of Traditional Chinese Medicine, No.1166, Liutai Road, Wenjiang District, \\ Chengdu 611137, China
}

*For correspondence: Email: hqwan2163@163.com

\begin{abstract}
Purpose: To investigate the effect of crude polysaccharide isolated from pao-tian-xiong on chronic renal failure in mice, and its monosaccharide composition.

Methods: Male Kunming mice were orally treated with adenine $(211.5 \mathrm{mg} / \mathrm{kg} /$ day) for 7 days, followed by either crude polysaccharides $(125,250$ or $500 \mathrm{mg} / \mathrm{kg}$ ), or positive drug solution (jinguishenqi pill, $2000 \mathrm{mg} / \mathrm{kg}$ ) for another 7 days (each group had 15 mice). Mice in normal and negative control groups were given saline. Mental and physical states, blood urine nitrogen (BUN) and serum creatinine (SCr), kidney morphological changes and organ indices were determined. Histopathological examination of spleen and kidney tissues was also performed. The monosaccharide composition of crude polysaccharide was determined by high-performance liquid chromatography (HPLC) and gas chromatography and mass spectrometry (GC-MS).

Results: Compared with negative control group, serum BUN (6.71 mmol/L vs. $8.61 \mathrm{mmol} / \mathrm{L})$ and $\mathrm{Cr}$ (107.74 vs. $113.39 \mu \mathrm{mol} / \mathrm{L})$ were significantly decreased by the crude polysaccharide isolate $(p<0.05)$, whereas epididymis index (0.2556 vs. $0.2135 \%)$ and seminal vesicle index $(0.5547$ vs. $0.3945 \%)$ were increased $(p<0.05)$. Histopathological examination showed that injuries to kidney, spleen, testis and epididymis decreased significantly. The crude polysaccharides contained mainly glucose, rhamnose, arabinose, galactose, mannose, galacturonic acid, glucuronic acid and xylose, and their contents ranged from 0.7 to $65 \%$.

Conclusion: These results suggest that the crude polysaccharides of Pao-tian-xiong ameliorates CRF symptoms in mice, thereby providing experimental evidence in support of its use as an anti-CRF drug.
\end{abstract}

Keywords: Pao-tian-xiong, Radix Aconiti Lateralis Preparata, Crude polysaccharides, Chronic kidney disease, Monosaccharide composition, Adenine, Renal injury

This is an Open Access article that uses a fund-ing model which does not charge readers or their institutions for access and distributed under the terms of the Creative Commons Attribution License (http://creativecommons.org/licenses/by/4.0) and the Budapest Open Access Initiative (http://www.budapestopenaccessinitiative.org/read), which permit unrestricted use, distribution, and reproduction in any medium, provided the original work is properly credited.

Tropical Journal of Pharmaceutical Research is indexed by Science Citation Index (SciSearch), Scopus, International Pharmaceutical Abstract, Chemical Abstracts, Embase, Index Copernicus, EBSCO, African Index Medicus, JournalSeek, Journal Citation Reports/Science Edition, Directory of Open Access Journals (DOAJ), African Journal Online, Bioline International, Open-J-Gate and Pharmacy Abstracts

\section{INTRODUCTION}

Chronic renal failure (CRF) is a serious kidney disease with increasing prevalence which has made it a global public health problem [1]. Compared to other diseases, CRF patients need more frequent and long-term hospital treatment, and they have poor quality of life and high 
morbidity and mortality [2,3]. Therefore, it is important to develop new drugs for treating CRF. Increasing corpus of evidence have demonstrated that traditional Chinese medicines (TCMs) are reliable complementary and alternative strategies for treating some serious medical problems [4]. Moreover, several studies have demonstrated that polysaccharides extracted from TCMs such as Radix Astragali seu Hedysari (Leguminosae) [5], Cordyceps sobolifera [6], Mori ramulus [7], Dipsaci radix [8], and Codonopsis radix [9] have potential therapeutic effects on CRF-related symptoms.

Studies on polysaccharides from fuzi have so far focused on antibacterial effects against Escherichia coli and Staphylococcus aureus [10], anti-hyperglycemia [11], anti-tumor [12], antihypercholesterolemia [13], anti-hepatic ischemiareperfusion injury [14], and immuno-enhancing effects [15]. However, not much is known about the effect of pao-tian-xiong (Figure1), which is one of the processed products of fuzi, and the effect of its polysaccharide (PPTX) on CRF in an animal model. Therefore, the aim of the present study was to investigate the effect of PPTX on adenine-induced CRF in mice, as well as its monosaccharide composition using HPLC-precolumn derivatization and GC-MS.
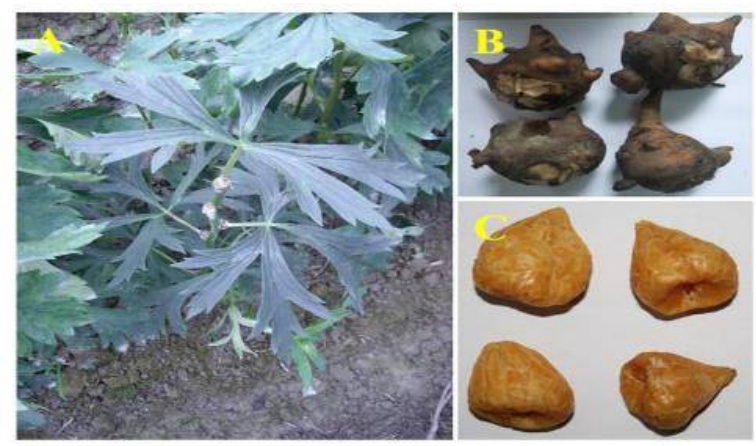

Figure 1: Aconitum carmichaelii Debx. (A) Whole plant of $A$. carmichaelii; (B) fresh lateral roots of $A$. carmichaeli; (C) processed product of lateral roots of A. carmichaeli (pao-tian-xiong)

\section{EXPERIMENTAL}

\section{Materials}

Rhamnose, xylose, L-arabinose, mannose, glucose and D-galactose were purchased from Chengdu Pufeide Biological Technology Co. Ltd. (Chengdu, China). D-Glucuronic acid and D-(+)galacturonic acid were purchased from Hefei Biotech. Ltd (Hefei, China). Dialysis bag (molecular intercept 3500), $\alpha$-amylase and papain were products of $\mathrm{Ru} \mathrm{Ji}$ Biotech. Ltd. (Chengdu, China). Pyridine, 3-fluoroacetic acid
(TFA), acetic anhydride and chloroform were of analytical grade. Urea determination kit (urease indophenol method) and creatinine (Cr) assay kit (1:1, picric acid method) were purchased from Changchun Huili Biotech. Co. Ltd (Changchun, China).

\section{Preparation of PPTX}

Pao-tian-xiong was purchased from the Sichuan Good Doctor Panxi Pharmaceutical Co. Ltd (Sichuan, China), and authenticated by Professor Xianming Lu of Chengdu University of Traditional Chinese Medicine (voucher number 201602150003ptx). Pao-tian-xiong was extracted twice with distilled water $(1: 10, w / v)$ under reflux at $100{ }^{\circ} \mathrm{C}$ for $1 \mathrm{~h}$, and the supernatant was concentrated to $0.5 \mathrm{~g} / \mathrm{mL}$. The supernatant was precipitated overnight at $4^{\circ} \mathrm{C}$ with $95 \%$ ethanol kept. The crude polysaccharides precipitate was dried using vacuum freeze-dryer, and then ground to powder. The powder was dissolved in distilled water containing $1 \%(\mathrm{~m} / \mathrm{v})$ a-amylase at $60{ }^{\circ} \mathrm{C}$ in a water bath for $3 \mathrm{~h}$. Then, a boiling water bath was used to inactivate amylase for 5 $\min$. Thereafter, $0.1 \%(\mathrm{~m} / \mathrm{v})$ papain was added to the solution at $40^{\circ} \mathrm{C}$ and $\mathrm{pH} 6$ for $2 \mathrm{~h}$. The $\mathrm{pH}$ of the solution was adjusted to $7.0-8.5$, followed by immersion in a $100^{\circ} \mathrm{C}$-water bath to inactivate papain. Protein was removed using the Sevage method (chloroform-butanol $=4: 1 \mathrm{v} / \mathrm{v}$ ). The polysaccharide solution was decolorized with activated carbon, and subjected to dialysis in a dialysis bag (molecular interception = $3500 \mathrm{KD}$ ) in distilled water. After the dialysis, the solution was freeze-dried [16]. The yield of pao-tian-xiong polysaccharide (PPTX) was $2.0 \%$.

\section{Animals and treatments}

A total 90 Kunming-species male mice weighing 30-35 g, were purchased from Chengdu Dashuo Experimental Animal Co. Ltd. (Chengdu, China). The mice were reared under appropriate conditions in an environment containing 50-60\% humidity, and at a constant temperature of $20 \pm 3$ ${ }^{\circ} \mathrm{C}$. Before the experiment, all mice were housed and acclimatised to the laboratory environment for 3 days, during which they were permitted ad libitum access to feed and drinking water.

Thereafter, 90 male mice were randomly divided into two groups: normal control group (containing 15 mice), and negative control group (with 75 mice). Mice in the negative control group were gavaged with adenine at a dose of $211.5 \mathrm{mg} / \mathrm{kg}$ body weight (bwt), while mice in the normal control group were administered an equivalent volume of physiological saline. All the animals were treated orally daily for 7 consecutive days. 
Mice in the negative control group appeared emaciated. Moreover, they formed clusters, arched their backs, curled up, and manifested slow responses, poor appetite and increased thirst for water.

On the $8^{\text {th }}$ day, mice in negative control group were randomly divided into five groups: PPTX low dose group (125 mg/kg), PPTX medium group (250 mg/kg), PPTX high dose group (500 $\mathrm{mg} / \mathrm{kg}$ ), JGP group, and negative control group (15/group). In the next 7 days, mice in the low, medium and high dose PPTX groups received orally, PPTX solution at doses of 125, 250 and $500 \mathrm{mg} / \mathrm{kg}$, respectively, while the JGP mice were given jinguishenqi pill solution at a dose of $2000 \mathrm{mg} / \mathrm{kg}$ through the same route. Mice in the negative control group and normal control group were given equivalent volume of physiological saline. The treatments lasted for 14 days. The animal studies were handled as per the National Institute of Health, USA Guidelines for Care and Use of Laboratory Animals [17]. All experimental protocols were approved by Animal Care and Use Committee of Chengdu Municipal Hospital of Traditional Chinese Medicine, Chengdu, China [approval no. SCXK (chuan) 2015-3].

\section{Determination of serum levels of BUN and Creatinine (Cr)}

At the last day of the experiment, blood samples were collected from the eyes of the mice. After standing for $2 \mathrm{~h}$, the blood samples were centrifuged at $3000 \mathrm{rpm}$ for $10 \mathrm{~min}$, and the serum samples were kept frozen at $-80{ }^{\circ} \mathrm{C}$ prior use for assay of BUN and $\mathrm{SCr}$ using diagnostic kits according to the manufacturer's instructions.

\section{Evaluation of organ indices}

The blood, kidney, testes, epididymis and spleen were excised after blood collection and weighed immediately. Organ index (OI) was determined in terms of ratio of organ weight to body weight as shown in Eq 1.

Ol $(\%)=W_{0} / W_{1} \times 100$

where $W_{0}$ is the weight of organ, and $W_{1}$ is the body weight.

\section{Histopathological examination}

The organs were fixed in formalin (10\%), and sections were stained with hematoxylin and eosin (H\&E), examined under the light microscope, and photographed.

\section{Determination of monosaccharide composition of PPTX}

The sample (PPTX, $20 \mathrm{mg}$ ) was added to $2 \mathrm{~mL}$ of $2 \mathrm{mM}$ sulfuric acid. After $4 \mathrm{~h}$ of hydrolysis in an oven at $110^{\circ} \mathrm{C}$, the solution was neutralized with $8 \mathrm{~mol} / \mathrm{L}$ sodium hydroxide, and then diluted to 5 $\mathrm{mL}$ with water. The supernatant obtained after centrifugation was used for determination of monosaccharide composition. L-Rhamnose monohydrate, xylose, L-arabinose, mannose, glucose, D-galactose, D-glucuronic acid, a-Dgalacturonic acid monohydrate were weighed and dissolved in separately in distilled water to yield concentrations of $1.041 .10,1.54,1.14$, $1.59,0.98,1.01$ and $1.50 \mathrm{mg} / \mathrm{mL}$. Then, $100 \mu \mathrm{L}$ of each standard solution was diluted to $1 \mathrm{~mL}$, and the standard solutions were mixed.

\section{Preparation of derivatized products}

Two hundred microliter of the sample solution was added to $200 \mu \mathrm{L}$ PMP solution $(0.5 \mathrm{M}$ in methanol) and $200 \mu \mathrm{L}$ of $\mathrm{NaOH}(0.3 \mathrm{M})$. The mixture was incubated at $70{ }^{\circ} \mathrm{C}$ for $30 \mathrm{~min}$, cooled to room temperature and neutralized with $200 \mu \mathrm{L}$ of $0.3 \mathrm{HCl}(0.3 \mathrm{M})$. Then, $1 \mathrm{~mL}$ of chloroform was add4ed to the mixture. After vigorous vortexing and standing for $10 \mathrm{~min}$, the organic phase was carefully discarded. The above procedure was repeated 3 times. The aqueous layer was then centrifuged at $1600 \mathrm{rpm}$ for $10 \mathrm{~min}$. The supernatant was passed through a $0.45 \mu \mathrm{m}$ syringe filter before HPLC analysis. The standard solutions were treated as described above. The negative control solution was also treated as described above, except that no sample was added.

\section{HPLC conditions}

Octadecylsilane chemically bonded to silica was used as filler. The mobile phase was acetonitrile (A) mixed with phosphate-buffered saline (PBS, $\mathrm{pH}$ 6.8). The gradient elution was performed with $16-18 \%$ (A) for $30 \mathrm{~min}$, with an injection volume of $20 \mu \mathrm{L}$ and eluent flow rate of $1 \mathrm{~mL} / \mathrm{min}$ at 30 ${ }^{\circ} \mathrm{C}$. The detection wavelength was $250 \mathrm{~nm}$.

\section{GC-MS analysis of PPTX}

\section{Acetylation of PPTX and preparation of monosaccharide standards}

The sample (PPTX, $10 \mathrm{mg}$ ) was hydrolysed with $2 \mathrm{~mL}$ of $2 \mathrm{M}$ trifluoroacetic acid (TFA) at $110^{\circ} \mathrm{C}$ for $4 \mathrm{~h}$ in a sealed glass tube. Excess acid was completely removed by repeated decompression distillation with methanol. Five milligram of monosaccharide standard and hydrolysed PPTX 
were added to $10 \mathrm{mg}$ of hydroxylamine hydrochloride and $0.5 \mathrm{~mL}$ of pyridine in water bath at $90{ }^{\circ} \mathrm{C}$ for $30 \mathrm{~min}$. Thereafter, the solution was cooled to room temperature. Then, $1 \mathrm{~mL}$ of acetic anhydride was added to the solution, and the resultant solution was heated in water bath at $90{ }^{\circ} \mathrm{C}$ for $30 \mathrm{~min}$, and cooled to room temperature. The solution was evaporated to dryness under reduced pressure at $70{ }^{\circ} \mathrm{C}$. The residue was dissolved in $2 \mathrm{~mL}$ of chloroform and filtered through $0.22 \mu \mathrm{m}$ syringe filter before GC analysis [18].

\section{GC-MS operating conditions}

HP-5MS capillary column $(30 \mathrm{~m} \times 250 \mu \mathrm{m} \times 0.25$ $\mu \mathrm{m})$ was used with nitrogen as carrier gas at a flow rate of $1.0 \mathrm{~mL} / \mathrm{min}$. The injector temperature was set at $280^{\circ} \mathrm{C}$, and detector temperature was $230{ }^{\circ} \mathrm{C}$. The column temperature was initially programmed at $60^{\circ} \mathrm{C}$, then raised to $120^{\circ} \mathrm{C}$ at the rate of $10^{\circ} \mathrm{C} / \mathrm{min}$, ramped up to $220^{\circ} \mathrm{C}$ at the rate of $20{ }^{\circ} \mathrm{C} / \mathrm{min}$, and finally to $280^{\circ} \mathrm{C}$ at 10 ${ }^{\circ} \mathrm{C} / \mathrm{min}$. Split injection was applied with volume of $1.0 \mu \mathrm{L}$ and split ratio of $5: 1$. The scanning range was from 35 to 550 amu. The GC analysis was carried out using total ion flow peak retention time.

\section{Statistical analysis}

Data are presented as mean \pm standard deviation (mean \pm SD). One-way analysis of variance (ANOVA) was conducted using SPSS 21.0 (SPSS, Chicago, IL, USA) for determination of differences among groups. If homogeneity of variance was present, LSD or Bonferroni test was used. Otherwise, Dunnett's or Tamhane's test was performed. Differences were considered statistically significant at $p<0.05$ and highly statistically significant at $p<0.01$.

\section{RESULTS}

\section{Effect of PPTX on CRF mice}

During model establishment and drug administration, 6 mice died in all. The deaths might have been caused by numerous factors such as the drug used in the model preparation, individual differences, or experimental operations. In the normal group, the mice were very active, with thick and shiny hair, normal feed and water intake, quick reflexes, and normal urination during the experiment. However, one week after model establishment, the mice began to lose hair, and became sensitive to cold, which resulted in clustering. Compared to the normal control group, mice in the negative control group were less active, ate less, and drank more water, urinated more, lost weight, had cold limbs, were slow in their reflexes, and were uninterested in their environment. In the three PPTX groups and JGP group, the frequency of independent activity improved, and urination and hair condition seemed to recover gradually as before the experiment. The frequency of independent activity is shown in Table 1.

Table 1: The effect of PPTX on frequency of independent activity

\begin{tabular}{lcc}
\hline Group & $\mathbf{n}$ & $\begin{array}{c}\text { Frequency of } \\
\text { independent } \\
\text { activity }\end{array}$ \\
\hline Normal & 15 & $100.77 \pm 25.46$ \\
Negative control & 14 & $71.86 \pm 17.36^{\#}$ \\
PPTX low dose & 14 & $76.43 \pm 14.43$ \\
PPTX medium dose & 14 & $75.86 \pm 15.06$ \\
PPTX high dose & 13 & $80.00 \pm 14.10$ \\
JGP & 14 & $82.71 \pm 22.57$
\end{tabular}

The results are expressed as mean \pm SD; ${ }^{\#} p<0.05$, vs. normal group

\section{Effect of PPTX on body weight}

As shown in Table 2, before the experiment, there were no significant differences in body weight among 6 groups. However, within 7 days of model preparation, the body weights of ice in the normal group were higher than those of the other five groups. On the $10^{\text {th }}$ day, i.e. 3 days after the treatment, mice in the normal control, negative control, PPTX low dose, PPTX medium dose, PPTX high dose and JGP groups gained weight by $1.74,1.32,2.24,4.40,2.29$ and 5.00 $\%$, respectively. On $14^{\text {th }}$ day, mice in normal group lost weight by $2.13 \%$, while mice in the negative control, PPTX low dose, PPTX medium dose, PPTX high dose and JGP groups gained weight by $2.61,3.42,3.60,6.07$ and $4.01 \%$, respectively. However, compared with day 0 , mice in the normal group gained weight, while mice in the other mice lost weight. These data indicate that PPTX prevents weight loss in CRF mice.

\section{Effect of PPTX on organ indices}

Compared with normal group, the kidney indices and testis indices in negative control group were significantly increased, while seminal vesicle indices decreased significantly $(p<0.01)$. However, the decreases in spleen index and epididymis index were not statistically significant $(p>0.05)$. There were no statistically significant differences in the five index values between the PPTX low dose and medium dose groups. However, the medium dose PPTX had the tendency of improving organs through increases in seminal vesicle index and epididymis index, and decreases in kidney index.

Trop J Pharm Res, June 2019; 18(6): 1238 
Table 2: Changes in body weight of CRF mice

\begin{tabular}{lccccc}
\hline Group & $\mathbf{N}$ & day 0 $\mathbf{~ g})$ & $\mathbf{7}^{\text {th }}$ day(g) & $\mathbf{1 0}^{\text {th }}$ day(g) & $\mathbf{1 4}^{\text {th }}$ day(g) \\
\hline Normal & 15 & $30.58 \pm 1.42$ & $34.48 \pm 1.62$ & $35.08 \pm 1.44$ & $34.33 \pm 2.09$ \\
Negative control & 14 & $30.62 \pm 0.99$ & $24.87 \pm 2.19^{\# \#}$ & $25.20 \pm 2.72^{\text {\#\# }}$ & $25.83 \pm 1.94^{\# \#}$ \\
PPTX low dose & 14 & $30.14 \pm 1.13$ & $25.42 \pm 2.52$ & $25.99 \pm 1.78$ & $26.88 \pm 1.43$ \\
PPTX medium dose & 14 & $30.73 \pm 1.04$ & $25.25 \pm 2.46$ & $26.36 \pm 1.87$ & $27.31 \pm 2.15$ \\
PPTX high dose & 13 & $30.33 \pm 0.82$ & $25.29 \pm 1.84$ & $25.87 \pm 2.03$ & $27.44 \pm 1.93$ \\
JGP group & 14 & $30.44 \pm 1.00$ & $24.95 \pm 1.75$ & $26.19 \pm 1.80$ & $27.24 \pm 2.48$ \\
\hline
\end{tabular}

The results are expressed as mean $\pm S D ;{ }^{\#} p<0.01, v s$. normal group

Table 3: Effect of PPTX on organ index values

\begin{tabular}{llllll}
\hline Group & Kidney & Spleen & Testis & Epididymis & Seminal vesicle \\
\hline Normal & $1.5927 \pm 0.1053$ & $0.4147 \pm 0.0991$ & $0.7395 \pm 0.0750$ & $0.2294 \pm 0.0338$ & $0.6414 \pm 0.1809$ \\
Negative control & $1.9100 \pm 0.2565^{\# \#}$ & $0.3698 \pm 0.0472$ & $0.8826 \pm 0.1498^{\# \#}$ & $0.2135 \pm 0.0397$ & $0.3945 \pm 0.0725^{\# \#}$ \\
PPTX low dose & $1.9012 \pm 0.2207$ & $0.3875 \pm 0.0562$ & $0.8634 \pm 0.0975$ & $0.2098 \pm 0.0367$ & $0.4176 \pm 0.0986$ \\
PPTX medium dose & $1.7783 \pm 0.2609$ & $0.3634 \pm 0.0452$ & $0.8463 \pm 0.1325$ & $0.2421 \pm 0.0289$ & $0.4512 \pm 0.0726$ \\
PPTX high dose & $1.7268 \pm 0.1555^{*}$ & $0.3936 \pm 0.0735$ & $0.8560 \pm 0.1295$ & $0.2556 \pm 0.0387^{*}$ & $0.5547 \pm 0.1297^{\star *}$ \\
JGP & $1.7939 \pm 0.3285$ & $0.4343 \pm 0.0751^{*}$ & $0.8168 \pm 0.0730$ & $0.2596 \pm 0.0303^{*}$ & $0.4647 \pm 0.1350$ \\
Results are expressed as mean \pm SD. ${ }^{\# \#} p<0.01, v s$. normal group; ${ }^{*} p<0.05,{ }^{* *} p<0.01, v s$. negative control \\
\multicolumn{2}{l}{ group }
\end{tabular}

Table 4: Effect of PPTX on levels of BUN and SCr

\begin{tabular}{lccc}
\hline Group & $\mathbf{n}$ & SCr $(\boldsymbol{\mu m o l} / \mathbf{L}$ & BUN (mmol/L) \\
\hline Normal & 15 & $113.39 \pm 26.85$ & $4.76 \pm 0.87$ \\
Negative control & 14 & $149.83 \pm 28.97^{\# \#}$ & $8.61 \pm 2.96^{\# \#}$ \\
PPTX low dose & 14 & $139.76 \pm 25.07$ & $8.09 \pm 1.41$ \\
PPTX medium dose & 14 & $130.34 \pm 26.07$ & $7.86 \pm 1.31$ \\
PPTX high dose & 13 & $107.74 \pm 19.71^{* *}$ & $6.71 \pm 2.33^{*}$ \\
JGP & 14 & $105.73 \pm 28.09^{* *}$ & $7.16 \pm 1.96$
\end{tabular}

Results are expressed as mean \pm SD; ${ }^{\#} p<0.05,{ }^{\# \#} p<0.01$, vs. normal group; ${ }^{\star} p<0.05,{ }^{* *} p<0.01$, vs. negative control group

In PPTX high dose group, epididymis and seminal vesicle indices were increased significantly $(p<0.05)$, while kidney index decreased significantly $(p<0.05)$, when compared with mice in the negative control group. In the JGP group, spleen index and epididymis index were significantly increased ( $p$ $<0.05$ ). These results (shown in Table 3) indicate that PPTX (especially at high dose) repairs damages to kidney, epididymis and seminal vesicle.

\section{Effect of PPTX on serum levels of BUN and $\mathrm{Cr}$}

As shown in Table 4, in the negative control group, significant increases in levels of BUN and $\mathrm{Cr}$ were observed, when compared with normal group $(p<0.01)$. The treatment groups had lower levels of BUN and SCr than the negative control group. However, high-dose PPTX led to significant decreases in BUN and SCr $(p<0.05)$, indicating that PPTX restored homeostasis in serum BUN and $\mathrm{Cr}$. There was significantly difference in SCr level between the JGP and negative control groups $(p<0.01)$.

\section{Effect of PPTX on morphology and pathology of CRF mice}

The morphological changes in kidneys were visually inspected. In the normal control mice group, the kidneys were normal, and were reddish-brown and smooth on the surface. In contrast, the negative control mice group had pale and swollen kidneys with dark spots on the surface. However, treatment with PPTX (at the three doses) and JGP relieved the kidney pathologies, with kidney colour between reddish brown and pale, and relatively less spots on the kidney surface (Figure 2). Representative photomicrographs of kidneys, testis, epididymis and spleen, as revealed through $\mathrm{H} \& \mathrm{E}$ staining were observed under a light microscope.

Compared with normal group, negative control group developed pathological changes in kidneys involving glomerular necrosis, mass hyperplasia of fibrous tissue in the interstitium, infiltration of inflammatory cells, necrosis of renal tubules, and exudation of purulent cells. In addition, there were degeneration or necrosis of spermatogenic cells in the testis, decrease in the number of sperm in the epididymis, and neutrophil 
infiltration in the red pulp of the spleen. However, after treatment with PPTX and JGP, these changes were alleviated, and even reversed to the normal state in a dose-dependent manner. The photomicrographs of kidneys, testis, epididymis and spleen are shown in Figure 3.
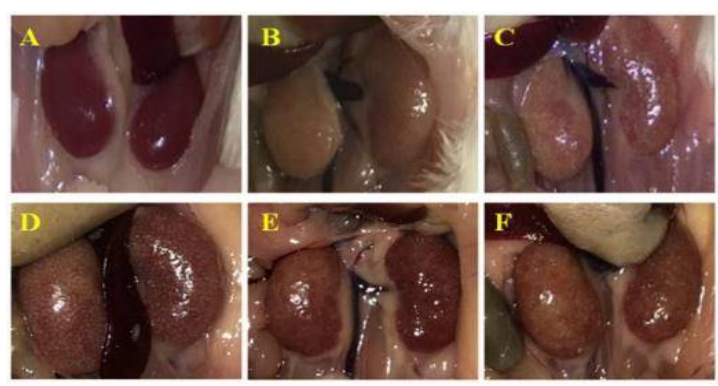

Figure 2: Kidney morphologic changes in PPTX treated mice. $A$ to $F$ represent normal, negative control, PPTX low dose, PPTX middle dose, PPTX high dose, and JGP groups

\section{Monosaccharide composition of PPTX}

As shown in Table 5, the correlation coefficient was over 0.999, suggesting that the HPLC method was well established. Therefore the percentage monosaccharide content of PPTX was measured in terms of regression equation. From the present study, the main monosaccharides in PPTX were mannose (4.297 $\%)$, D-glucuronic acid (0.94 \%), rhamnose (5.79 $\%)$, D-(+)-galacturonic acid (2.47 \%), glucose $(65.28 \%)$, D-galactose $(4.36 \%)$, xylose $(0.71 \%)$ and L-arabinose (5.08\%) (Table 6). GC-MS analysis was carried out using total ion flow peak retention time and mass spectrometry from standard monosaccharides (Figure 4 and Table 7). As shown in Figure 4, Figure 5, Figure 6; and Table 8, Small amount of talose, lactose, cellobiose, melibiose, trehalose were present in PPTX.

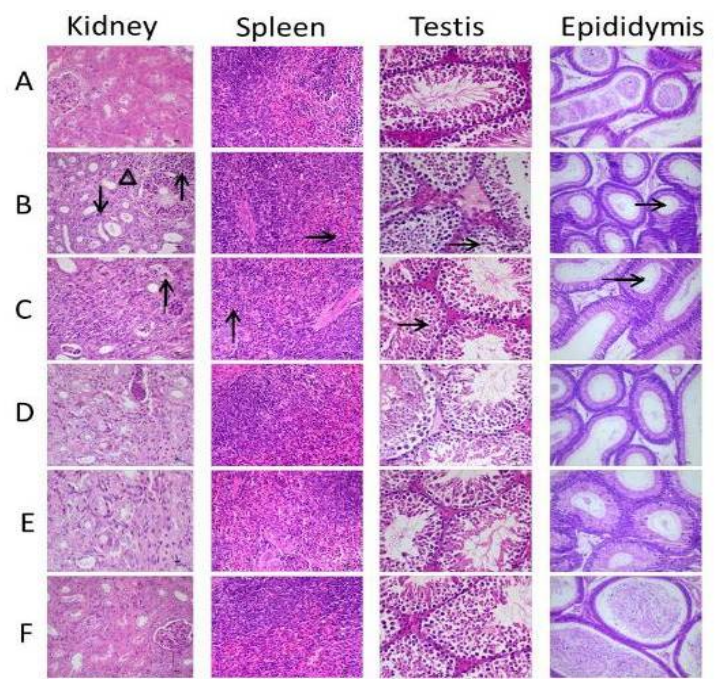

Figure 3: Photomicrographs of organ and tissues (H\&E staining; $\times 400$ ). A to $F$ represent normal, negative control, PPTX low dose, PPTX middle dose, PPTX high dose, and JGP groups. For kidney, upward arrow shows mass hyperplasia of fibrous tissue in the interstitium or glomerular necrosis, downward arrow means infiltration of inflammatory cells, triangle indicates exudation of purulent cells. For spleen, arrow represents neutrophils infiltration in the red pulp of the spleen. For testis, arrow means exfoliation or necrosis of spermatogenic cells. For epididymis, arrow means decrease in the number of sperm

Table 5: Regression equations and linear ranges of monosaccharide standard by HPLC

\begin{tabular}{llll}
\hline Monosaccharide & $\begin{array}{l}\text { Correlation } \\
\text { coefficient }\left(r^{2}\right)\end{array}$ & Regression equation & Linear range $/ \boldsymbol{\mu g}$ \\
\hline Man & 1 & $y=13786 x-28.149$ & $0.0570-0.4275$ \\
Glca & 0.9999 & $y=4726.6 x-53.136$ & $0.0505-0.3788$ \\
Rha & 0.9996 & $y=6792.8 x-81.893$ & $0.0520-0.3900$ \\
Gala & 0.9999 & $y=13762 x-94.721$ & $0.0750-0.5625$ \\
Glc & 0.9996 & $y=4560.3 x-95.857$ & $0.0795-0.5962$ \\
Gal & 1 & $y=8834.4 x-65.641$ & $0.0490-0.3675$ \\
Xyl & 1 & $y=12998 x-102.86$ & $0.0550-0.4125$ \\
Ara & 1 & $y=13725 x-116.47$ & $0.0770-0.5775$ \\
\hline
\end{tabular}

Table 6: Monosaccharide composition of PPTX (\%)

\begin{tabular}{llllllll}
\hline Man & Glc & Rha & Gala & Glc & Gal & Xyl & Ara \\
\hline $4.2966 \pm$ & $0.9401 \pm$ & $5.7875 \pm$ & $2.4745 \pm$ & $65.2808 \pm$ & $4.3568 \pm$ & $0.7133 \pm$ & $5.0792 \pm$ \\
0.1164 & 0.0376 & 0.1785 & 0.0546 & 0.3126 & 0.0585 & 0.0103 & 0.0836 \\
\hline Values are & mean $\pm S D$ & & & &
\end{tabular}



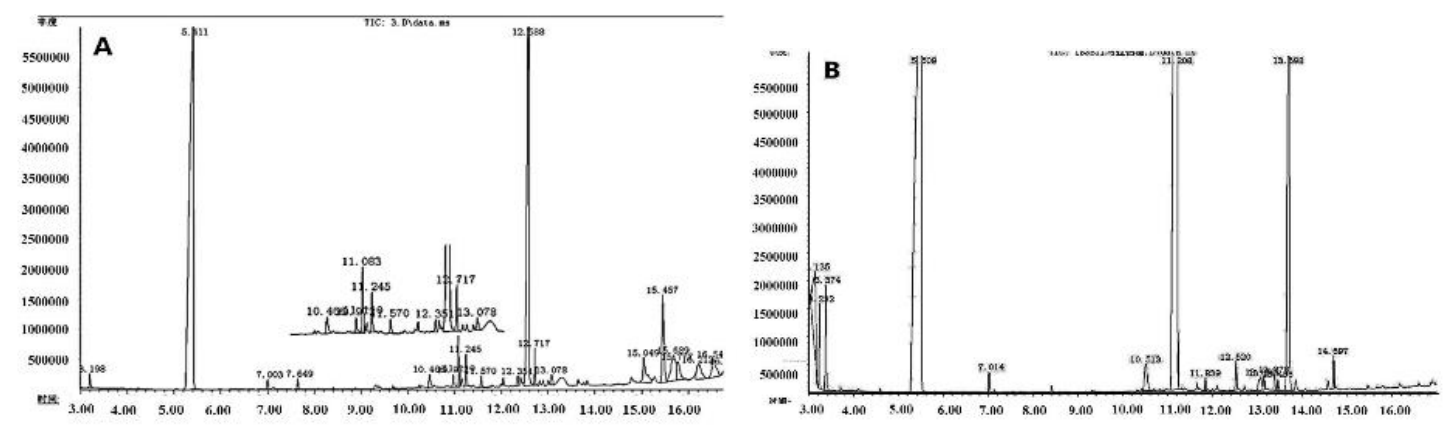

Figure 4: GC-MS total ion chromatogram of PPTX. Key: $A=$ PPTX and B = arabinose (Ara)

Table 7: GC-MS analysis of monosaccharide standards

\begin{tabular}{lllc}
\hline $\begin{array}{l}\text { Retention } \\
\text { time (min) }\end{array}$ & Monosaccharide & Monosaccharide derivative & $\begin{array}{c}\text { Matching percentage } \\
(\%)\end{array}$ \\
\hline 11.092 & Rhamnose & L-(+)-Rhamnose, aldononitrile, tetraacetate & 90 \\
11.210 & Arabinose & DL-Arabinose, aldononitrile, tetraacetate & 90 \\
11.316 & Xylose & D-Xylononitrile,2,3,4,5-tetraacetate & 90 \\
12.622 & Mannose & D-(+)-Mannose, aldononitrile, pentaacetate & 90 \\
12.686 & Glucose & 2,3,4,5,6-Penta-O-acetyl-D-gluconitrile & 91 \\
12.857 & Galactose & D-(+)-Galactose, aldononitrile, pentaacetate & 91 \\
\hline
\end{tabular}
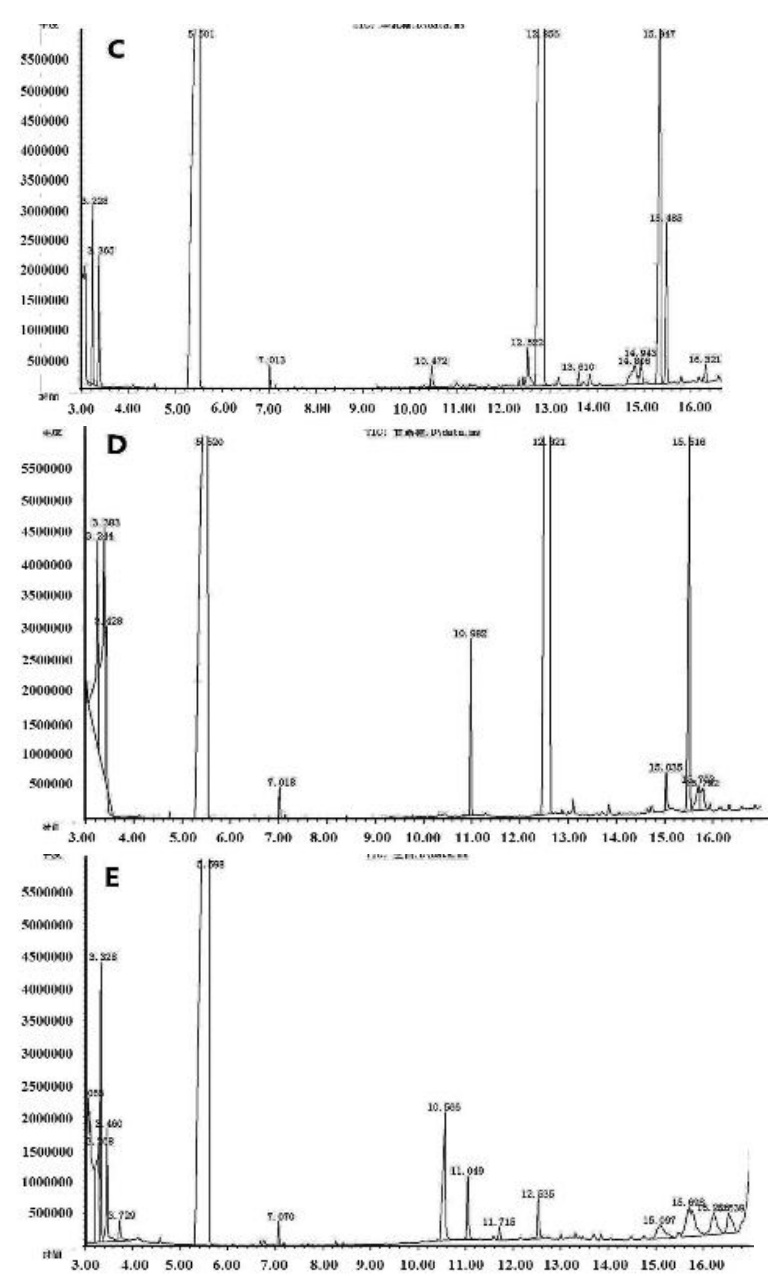

Figure 5: GC-MS total ion chromatogram of PPTX. Key: $\mathrm{C}=$ galactose (Gal), D = mannose (Man), $\mathrm{E}=$ blank
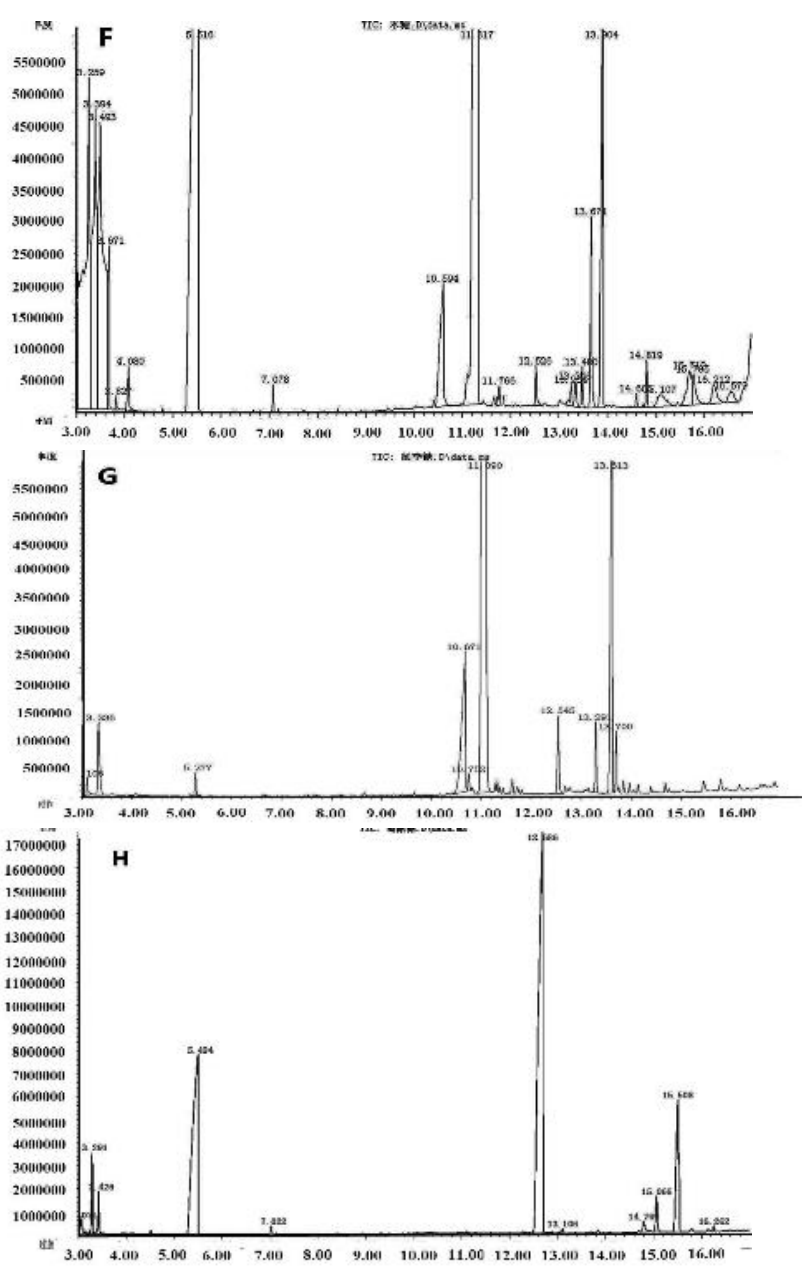

Figure 6: GC-MS total ion chromatogram of PPTX. Key: $\mathrm{F}=$ xylose $(\mathrm{Xyl}), \mathrm{G}=$ rhamnose $(\mathrm{Rha})$, and $\mathrm{H}=$ glucose (Glc) 
Table 8: GC-MS analysis of monosaccharides of PPTX

\begin{tabular}{lll}
\hline $\begin{array}{l}\text { Retention time } \\
\text { (min) }\end{array}$ & Monosaccharide derivative & $\begin{array}{l}\text { Monosaccharide } \\
\text { composition }\end{array}$ \\
\hline 10.975 & L-(+)-Rhamnose, aldononitrile, tetraacetate & Rhamnose \\
11.080 & DL-Arabinose, aldononitrile, tetraacetate & Arabinose \\
11.163 & D-Xylononitrile,2,3,4,5-tetraacetate & Xylose \\
12.351 & D-(+)-Talose, aldononitrile, pentaacetate & Talose \\
12.592 & D-(+)-Mannose, aldononitrile, pentaacetate & Mannose \\
12.716 & D-(+)-Galactose, aldononitrile, pentaacetate & Galactose \\
13.080 & D-Glucose, 2,3,4,5,6-pentaacetate & Glucose \\
15.457 & D-(+)-Lactose octaacetate & Lactose \\
16.210 & a-D-Cellobiose octaacetate & Cellobiose \\
16.803 & Melibiose octaacetate & Melibiose \\
16.821 & Trehalose octaacetate & Trehalose \\
\hline
\end{tabular}

\section{DISCUSSION}

It is well-known that natural herbal medicine is a good potential resource for some useful agents for treating various diseases. In TCM, $A$. carmichaelii is a known Chinese folk medicine used for treating some serious diseases such as organ failure, shock, and cancers [19]. Pao tianxiong is a clinically processed product of $A$. carmichaelii which is also used to treat organ failure [20]. The present study is the first to report that polysaccharides isolated from the pao-tianxiong possess promising therapeutic effect on adenine-induced CRF in mice.

Previous studies have demonstrated that an appropriate experimental animal model was essential for the pharmacological and pathological investigations of human diseases. Adenine is one of the most frequently used drugs for establishing CRF because, at large doses, it induces abnormalities in uric acid metabolism, resulting in abnormal increase in $\mathrm{Cr}$ and BUN, and inflammatory reactions which resemble those that occur in humans [21].

Currently, increasing evidence have demonstrated that polysaccharides derived from natural herbal medicines or foods are reliable and safe agents for treating some stubborn diseases via regulation of immunity [22, 23]. Interestingly, the present results revealed that PPTX has promising protective potential for body weight, and inhibits increases in serum $\mathrm{Cr}$ and BUN, as well as inflammatory reactions in multiple-organs (kidneys, testis, epididymis and spleen) induced by adenine administration in mice.

To determine the monosaccharide composition of PPTX, HPLC and GC-MS analysis were used. The results revealed that the main monosaccharide contents of PPTX were glucose, rhamnose and L- arabinose, followed by $D$ galactose, mannose, D- (+) - galacturonic acid, Dglucuronic acid, and xylose. Small amounts of talose, lactose, cellobiose, melibiose, trehalose were also seen.

\section{CONCLUSION}

Crude monkshood polysaccharide has been successfully isolated from Radix Aconiti Lateralis Preparata as a white powder which is readily soluble in water. The present investigations reveal that the polysaccharides from Pao-tianxiong have potential therapeutic effect on adenine-induced chronic renal failure in mice. Thus, the polysaccharide may be beneficial in the development of new candidate drugs from the well-known TCM pao-tian-xiong. However, further studies on its mechanism of action and the structure of the polysaccharide are needed.

\section{DECLARATIONS}

\section{Acknowledgement}

This work was supported by the Plan of Sichuan Provincial Science and Technology Department under grant no.18YYJC0976.

\section{Competing interests}

The authors declare that they have no competing interests.

\section{Contribution of authors}

We declare that this work was done by the authors named in this article and all liabilities pertaining to claims relating to the content of this article will be borne by the authors. Qw H, LW and Ry $F$ designed the research. Ry $F$ and LW performed this study. Fn $G$ and $Y \times G$ analysed the data. LW and Qw $\mathrm{H}$ wrote the paper. Yx G was responsible for the critical revision of the paper. All authors read and approved the final manuscript. 


\section{Open Access}

This is an Open Access article that uses a funding model which does not charge readers or their institutions for access and distributed under the terms of the Creative Commons Attribution License (http://creativecommons.org/licenses/by/ 4.0) and the Budapest Open Access Initiative (http://www.budapestopenaccessinitiative.org/rea d), which permit unrestricted use, distribution, and reproduction in any medium, provided the original work is properly credited.

\section{REFERENCES}

1. Jha V1, Garcia-Garcia G, Iseki K, Li Z, Naicker S, Plattner B, Saran R, Wang AY, Yang CW. Chronic kidney disease: global dimension and perspectives. Lancet 2013; 382: 260-272.

2. Allison SJ. Study warns of burgeoning health burden of CKD in China. Nat Rev Nephrol 2012; 8: 251.

3. Khan $Y H$, Mallhi TH, Sarriff $A$, Khan AH, Tanveer $N$. Prevalence of Chronic Kidney Disease in Asia: $A$ Systematic Review of Population-Based Studies. J Coll Physicians Surg Pak 2018; 28: 960-966.

4. Wu WY, Hou JJ, Long HL, Yang WZ, Liang J, Guo DA. TCM-based new drug discovery and development in China. Chin J Nat Med 2014; 12: 241-250.

5. Lian Y, Xie L, Chen M, Chen L. Effects of an astragalus polysaccharide and rhein combination on apoptosis in rats with chronic renal failure. Evid Based Complement Alternat Med 2014; 2014: 1-7.

6. Chyau CC, Chen CC, Chen JC, Yang TC, Shu KH, Cheng $\mathrm{CH}$. Mycelia glycoproteins from Cordyceps sobolifera ameliorate cyclosporine-induced renal tubule dysfunction in rats. J Ethnopharmacol 2014; 153: 650658.

7. Li X, Wang L, Gao X, Li G, Cao H, Song D, Cai S, Liang $T$, Zhang $B, D u$ G. Mechanisms of protective effect of Ramulus Mori polysaccharides on renal injury in high-fat diet/streptozotocin-induced diabetic rats. Cell Physiol Biochem 2015; 37: 2125-2134.

8. Cong G, Cui L, Zang M, Hao L. Attenuation of renal ischemia/reperfusion injury by a polysaccharide from the roots of Dipsacus asperoides. Int J Biol Macromol 2013; 56: $14-19$

9. Li Z, Zhu L, Zhang $H$, Yang J, Zhao J, Du D, Meng J, Yang $F$, Zhao $Y$, Sun $J$. Protective effect of a polysaccharide from stem of Codonopsis pilosula against renal ischemia/reperfusion injury in rats. Carbohydr Polym 2012; 90: 1739-1743.

10. Lin GM, Liu L, Shao W. Microcalorimetry studies on the antibacterial effect of crude monkshood polysaccharide. $J$ Zhejiang Univ Sci B 2011; 12: 563-567.

11. Wang BB, Wang JL, Yuan J, Quan QH, Ji RF, Tan $P$, Han J, Liu YG. Sugar composition analysis of Fuzi polysaccharides by HPLC-MSn and their protective effects on Schwann cells exposed to high glucose. Molecules 2016; 21:1-14.

12. Gao L, Zeng S, Pan L. Induction of differentiation of dendritic cells derived from hepatocellular carcinoma by Fuzi polysaccharides. Chin J Clin Oncol. 2012; 39: 882$885+894$.

13. Huang $X Q$, Tang J, Zhou $Q$, Lu HP, Wu YL, Wu WK. Polysaccharide from Fuzi (FPS) prevents hypercholesterolemia in rats. Lipids Health Dis 2010; 9: 9.

14. Lin S, Liu K, Wu W, Chen C, Wang Z, Zhang X. Study on pretreatment of FPS-1 in rats with hepatic ischemiareperfusion injury. Am J Chin Med 2009; 37: 323-37.

15. Gao T, Bi $H$, Ma S, Lu J. The antitumor and immunostimulating activities of water soluble polysaccharides from Radix Aconiti, Radix Aconiti Lateralis and Radix Aconiti Kusnezoffii. Nat Prod Commun 2010; 5: 447-455.

16. Chen Z, Zhang W, Tang X, Fan H, XieX, Wan Q, Wu X, Tang JZ. Extraction and characterization of polysaccharides from Semen Cassiae by microwaveassisted aqueous two-phase extraction coupled with spectroscopy and HPLC. Carbohydr Polym 2016; 144: 263-270.

17. Guide for the Care and Use of Laboratory Animals: 8 Edn. $\quad$ https://www.nap.edu/read/12910/chapter/1. Accessed 2 April 2019

18. Cheong KL, Wu DT, Deng $Y$, Leong F, Zhao J, Zhang WJ, Li SP. Qualitation and quantification of specific polysaccharides from Panax species using GC-MS, saccharide mapping and HPSEC-RID-MALLS. Carbohydr Polym 2016; 153: 47-54.

19. Liu S, Li F, Li Y, Li W, Xu J, Du H. A review of traditional and current methods used to potentially reduce toxicity of Aconitum roots in Traditional Chinese Medicine. J Ethnopharmacol 2017; 207: 237-250.

20. Fan $R$, Wang $L$, Huang $Q$, Wang J, Gao Y, Geng $F$. Study on the therapeutic effect of Paotianxiong on adenine Induced deficiency of kidney-yang model rats. Asia-Pac Tradit Med. 2018; 14: 16-20.

21. Togoe EB, Silva IS, Cury JL, Souza AS, Borges JH, Saturnino KC. Animal model of chronic kidney disease using a unilateral technique of renal ischemia and reperfusion in White New Zealand rabbits. Acta Cir Bras 2014; 29: 651-657.

22. Liao J, Li C, Huang J, Liu W, Chen H, Liao S, Chen H, Rui W. Structure characterization of honey-processed astragalus polysaccharides and its anti-inflammatory activity in vitro. Molecules 2018; 23: 168.

23. Zhao Q, Li J, Yan J, Liu S, Guo Y, Chen D, Luo $Q$. Lycium barbarum polysaccharides ameliorates renal injury and inflammatory reaction in alloxan-induced diabetic nephropathy rabbits. Life Sciences 2016; 157: 82-90. 